\title{
La ciudad como panacea: políticas culturales comunitarias y participación en Córdoba (Argentina)
}

\section{The city as a panacea: cultural policies and participation in Córdoba (Argentina)}

\section{Mariana Gutiérrez}

Instituto de Estudios en Comunicación, Expresión y Tecnologías, Córdoba, Argentina marucgutierrezQggmail.com

https://orcid.org/0000-0002-4035-5100

\section{Resumen}

Este artículo analiza las políticas culturales en el marco de la valorización global de las ciudades como escala ideal para la descentralización del poder político y la solución de problemas de democratización cultural. Se recogen antecedentes relevantes sobre las potencialidades y los límites del nivel local en el plano del gobierno, la participación ciudadana y las políticas culturales municipales. Luego, se reportan los resultados de una investigación reciente realizada en Córdoba (Argentina) a partir de entrevistas y análisis de documentos. Se concluye que la dimensión participativa de esas políticas se desenvuelve en un plano retórico y permite asignarle un rol más activo y propositivo a sus beneficiarios. A la par, dichas políticas culturales reciben legitimación dado que se conciben como otro ámbito en el que los ciudadanos pueden participar de los asuntos públicos, aunque las decisiones tomadas no sean sustanciales o las posibilidades de participación efectiva se distribuyan de manera desigual.

Palabras clave: Políticas culturales locales, Democratización cultural, Participación ciudadana, Gobiernos locales.

\section{Abstract}

This article analyzes cultural policies in the context of global appraisal of cities as the ideal scale to decentralize political power and to address problems of cultural democratization. Critical antecedents are collected on the possibilities and limits that the local level presents in the fields of government, municipal cultural policies, and citizen participation. Then, the results of a recent investigation carried out in Córdoba (Argentina) based on interviews and document analysis are reported. We conclude that the participatory dimension of these policies unfolds on a rhetorical level and assigns a more active and purposeful role to their beneficiaries. At the same time, these cultural policies are legitimized since they are conceived as another possible dimension to enhance participation of citizens in public affairs, even if the decisions taken are not substantial or participation is unevenly distributed.

Keywords: Local cultural policies, Cultural democratization, Citizen participation, Local governments. 


\section{Introducción}

La valorización de las ciudades, a las que se le adjudica un rol protagónico en la transformación social y el desarrollo, constituye un fenómeno de creciente relevancia. Sin embargo, el entusiasmo por la escala local ha sido catalizado por la difusión internacional de innovaciones en el ámbito de la acción pública que ya cuentan con varias décadas de expansión. Los fundamentos ideológicos de éstas pueden abarcar desde imaginarios comunalistas y municipalistas (Bookchin, 2015; Thompson, 2020) -que reivindican la defensa de los "comunes urbanos" y el derecho a la ciudad (Zárate, 2020) - , hasta una narrativa de reforma de la administración pública inspirada por el neoliberalismo (Christensen \& Lagreid en Dupin-Meynard \& Négrier, 2020).

En línea con los primeros y su ideal de descentralización democrática, hacia finales de la década de 1980 e inicios de los 1990s, en Latinoamérica se despliegan una serie de innovaciones participativas con el afán de mejorar la calidad de la democracia recientemente recuperada en el continente. La incorporación de la sociedad civil en la toma de decisiones de políticas públicas y al control democrático comienza a conceptualizarse como "participación ciudadana".

En afinidad con las segundas, en varios países de América Latina la adopción del Consenso de Washington y la ulterior jibarización del Estado nacional en su rol desarrollista implicó un auge descentralizador. Como corolario, y sumado al reflujo de la globalización, “los gobiernos locales emergieron a una mayoría de edad" (Mendes, 2012, p.130) asumiendo mayores responsabilidades en sus propios procesos de crecimiento.

Tras varias décadas de innovaciones democráticas en el ámbito local, diferentes voces críticas señalan que los estados han estimulando la participación de manera desigual. Esto permite reconocer la presencia tanto de "proyectos participativos construidos en torno a la profundización y expansión de la democracia participativa, como la permanencia de la lógica neoliberal y la reconfiguración del poder estatal por medio de la sociedad" (Sorribas \& Garay, 2014, p.40). De hecho, al analizar las "nuevas prácticas participativas" impulsadas por las élites políticas,
Moini (2017) observa que éstas son diseñadas y activadas para obtener el apoyo de las élites económicas y, al mismo tiempo, proteger las decisiones públicas de las consecuencias impopulares de las políticas neoliberales.

Por su parte, Dagnino lquien se ha ocupado de analizar el régimen democrático brasilero, la institucionalidad participativa de la región, y el vínculo entre cultura y polítical ha remarcado la presencia de una "confluencia perversa" entre el proyecto neoliberal y el proyecto democrático-participativo. Tal fenómeno provoca, según la autora, una crisis discursiva fundada en las referencias comunes que se utilizan tanto en un proyecto político como en el otro. Ambos "requieren una sociedad civil activa y propositiva". Sin embargo, avanzan "en direcciones opuestas y hasta antagónicas" (Dagnino, 2018, p.681).

En el campo de las políticas culturales (en tanto políticas estatales), en la década de 1990 los gobiernos locales también asumieron mayores responsabilidades que en décadas anteriores, cuando el protagonismo de los niveles nacional y provincial de toma de decisión era hegemónico (Tasat, 2009). En consonancia, el trabajo de Basile (2020) -que aborda la repercusión de ese auge en las políticas culturales de la ciudad de Córdoba-, corrobora la hipótesis de que en las últimas décadas del siglo XX se comienzan a priorizar las intervenciones locales por sobre las políticas culturales de base nacional. Según señala la autora, esto ocurre simultáneamente en varias urbes latinoamericanas, a partir de una nueva dinámica de articulación entre políticas culturales transversales y el desarrollo económico urbano. La lógica globalizante y la exacerbación del “modelo político económico neoliberal que, como parte de sus estrategias de descentralización, asignó nuevos roles a los gobiernos locales en el entramado internacional" (Basile, 2020, p.155), subyace a esos fenómenos.

Ahora bien, desde fines del siglo XX a la fecha, no sólo la intervención pública ha tenido mayor preeminencia en la formulación de políticas culturales, sino que también ha resonado el creciente protagonismo que adquiere la participación en las sociedades occidentales actuales. Así, el "giro participativo" (Bonet \& Négrier, 2018) de las políticas culturales tiene consecuencias en la vida cultural y en las estrategias que desarrollan actores e instituciones culturales. 
Al calor de estos fenómenos que se venían gestando desde finales del siglo $X X$, en diversos países y ciudades de América Latina emergen las denominadas políticas culturales de base comunitaria. Éstas, difundidas por una red de organizaciones autodenominadas Movimiento Cultura Viva Comunitaria, se presentan como una innovadora política cultural de corte participativo.

No obstante, el desarrollo de estas políticas se erige en la tensión entre el clima progresista de fomento de la participación de las organizaciones sociales en las acciones públicas y los procesos de configuración de lo global en lo local, producidas en el marco de la gobernanza neoliberal (Brown, 2016; Piñero, 2019). Este panorama implica, también, una disputa entre representaciones diferentes en torno a lo cultural y a la participación misma que se condensan (siempre de manera parcial y contingente) en las políticas culturales instituidas.

En relación a las políticas estatales de cultura comunitaria en Argentina, una investigación previa permitió abrir una serie de interrogantes en cuanto a los límites de su potencial democratizante y participativo (Sorribas \& Gutiérrez, 2020). Dicha indagación demostró que las políticas públicas de cultura subnacionales en Argentina y los mecanismos de participación en su definición e implementación siguen siendo un ámbito poco explorado, tanto por académicos como por los propios gobiernos locales. Por esa razón, este artículo analiza las políticas culturales locales en el marco de la valorización global de las ciudades como panacea ante problemas de la democratización cultural o para la descentralización del poder político.

Proponemos dos hipótesis de trabajo. Por un lado, que la escala local en las políticas culturales no significa mayores niveles de participación efectiva, sino que posibilita el uso instrumental de la participación como forma de legitimación de la acción pública. Por otro, que la participación real está limitada a las redes de actores públicos y sociales preexistentes, reforzando las conclusiones obtenidas en trabajos previos (Sorribas, Eberhart \& Gutiérrez, 2016; Sorribas \& Gutiérrez, 2021) sobre el funcionamiento de las instituciones participativas locales en Córdoba.

Para eso, en primer lugar, se reconstruyen antecedentes relevantes sobre las potencialidades y los límites de la escala local, en el plano del gobierno local, de la participación ciudadana y de las políticas culturales municipales.

En segundo lugar, a la luz de esos antecedentes, analizamos las concepciones de la participación subyacentes en las políticas culturales locales. Reportamos los resultados de un estudio cualitativo realizado en Córdoba (Argentina). Para dicha investigación, se realizaron dos entrevistas en profundidad con participantes de la sociedad civil en el Concejo Municipal de Cultura Comunitaria (realizadas en 2017 y 2020), dos entrevistas en profundidad con referentes de Cultura Viva Comunitaria que participaron en el proceso de redacción de la Ordenanza de Festejos Comunitarios del Carnaval y una entrevista estructurada con una funcionaria de la Dirección de Cultura Viva lex Dirección de Cultura Comunitarial. Además se recurrió a fuentes secundarias como el texto de las Ordenanzas 12500 y 12957 de la Municipalidad de Córdoba. Se analizó el corpus mediante un tipo de análisis de contenido cualitativo específico denominado análisis categorial temático (Gutiérrez, 2019).

\section{Antecedentes relevantes sobre las potencialidades y los límites de la escala local}

\subsection{Gobierno local y participación ciudadana}

Cierta literatura de corte politológico señala que el nivel de gobierno local está en mejores condiciones de favorecer la participación ciudadana. Para Pratchett, algunas instituciones cuasi-democráticas "fragmentarían a la comunidad al focalizar su accionar en asuntos que se corresponden a áreas particulares de servicios" (2004, p.359). Sin embargo, en el caso del gobierno local, en su carácter "multipropósito", albergaría la representación del interés general de la comunidad. En concomitancia, la mayor proximidad de las autoridades locales con la ciudadanía favorecería que se ocupen más directamente de los problemas y preocupaciones de ésta a través de políticas públicas pertinentes.

En cuanto a la participación ciudadana, ya sea a través de órganos de participación (concejos) o mediante procesos participativos, Pratchett (2004) 
señala que la escala local de gobierno es la apropiada para su desarrollo ya que facilita la accesibilidad y mayor compromiso entre la ciudadanía y las instituciones. Respecto de los órganos de participación, Pérezy Navarro (2000) sostienen que son innovaciones democráticas orientadas a adecuar las decisiones gubernamentales a las demandas o necesidades particulares planteadas por la ciudadanía, alejada de una concepción meramente electoral de participación, asociada comúnmente al nivel central o nacional. La posibilidad de generar políticas públicas más situadas, así mismo, tiene que ver con el desarrollo de la receptividad (responsiveness) por parte de las autoridades locales, "complementada y desafiada por las amplias oportunidades para la participación que las instituciones democráticas locales ofrecen a los ciudadanos" (Pratchett, 2004, p.361).

Como corolario, el gobierno local estaría dotado de cierta autonomía, entendida como capacidad de desarrollar la identidad local a través de los procesos políticos y de las "formas preferidas" de practicar la política respecto del nivel central. Las instituciones políticas locales serían el foro en el que se puede expresar esa identidad local (Pratchett, 2004).

No obstante, todo ese contexto aquí señalado (mayor cercanía entre representantes y representados y mayor influencia/centralidad de las decisiones que se toman en el marco de procesos deliberativos), no puede darse por sentado.

Según Sorribas \& Gutiérrez (2021), el nivel de gobierno local no garantiza per se la mayor participación ni incrementa las "virtudes cívicas" de las autoridades dado que el diseño institucional también tiene injerencia, propiciando u obstruyendo dichas posibilidades. En tanto y en cuanto el diseño de la institucionalidad participativa no contemple las asimetrías de poder, los dispositivos deliberativos/ participativos podrían fungir como instrumento de legitimación estratégica de la dominación política.

\subsection{Políticas culturales locales y de base co- munitaria en ciudades de América Latina}

A partir de la década de 1990, en el intento de fortalecer las democracias recién recuperadas así como sus instituciones, en América Latina la sociedad civil comienza a ser incorporada en la toma de decisiones y en distintos mecanismos de control de poderes. Este giro se ha denominado “participación ciudadana". En el terreno propio de las políticas culturales oficiales, la participación ciudadana en su versión asociada a órganos de participación cuenta con mayor desarrollo en Brasil. En ese sentido, las propuestas brasileñas han sido pioneras en la configuración de una institucionalidad participativa en áreas como la de cultura, contando con un Consejo Nacional de Política Cultural y con diferentes consejos en niveles subnacionales (Calabre, 2010; Rubim, Fernandes \& Rubim, 2010). La participación institucionalizada puede ser asociada, también, a procesos en los que se incluye a la ciudadanía por un corto período de tiempo y puede comprender acciones de incidencia o lobby con legisladores, reparticiones estatales locales y funcionarios para definir un programa concreto o diseñar una política sectorial. Durante el ciclo de gobiernos progresistas en la región, se formularon numerosos proyectos de ley en las áreas de cultura y comunicación que habían sido elaborados por diferentes sectores de la sociedad civil o a los que ésta había contribuido decididamente (Gutiérrez, 2019).

Sin embargo, las políticas públicas de cultura subnacionales en Argentina y los mecanismos de participación en su definición e implementación siguen siendo un ámbito poco explorado, tanto por académicos como por los propios gobiernos locales.

Mendes (2012), en su análisis sobre las políticas culturales locales de doce municipios de la provincia de Buenos Aires, concluye que en las políticas implementadas existen serios déficits de comunicación con los destinatarios de las políticas y con la sociedad civil en general. El discurso que prima es el de la democratización en el acceso a los bienes culturales, por lo que la participación de la ciudadanía es escasa.

Para distinguir ese modelo de "políticas culturales de democratización" de otras, en las que subyace un concepto de cultura diferente y se le atribuye otro rol al Estado y a la ciudadanía, Mendes (2015) propone una modelización tripartita, que supone otros dos tipos de políticas públicas de cultura, las políticas democráticas lo de "democracia cultural") y las políticas recursistas. 
Las primeras se caracterizan por asimilar la cultura con las bellas artes, con una concepción estética y vinculada a la historia y la filosofía occidentales. El rol del Estado tiene que ver con la preservación del patrimonio y la difusión de la producción artística y de la ciudadanía, y se espera que se eduque en base a ese saber "universal" y esos valores estéticos verdaderos.

Al hablar de políticas democráticas, Mendes hace referencia a la concepción de cultura en sentido antropológico, con un Estado que fomenta la "participación de la ciudadanía en la vida cultural" $(2015$, p.96) y, como consecuencia, se espera que esta cambie su actitud, desde la expectación a la participación.

Por último, el modelo recursista, difundido principalmente en la obra de Yúdice (2002 2019), concibe a la cultura como un recurso valioso para hacer frente a una serie de problemas o fenómenos que antes les eran ajenos. Por ejemplo, cuestiones relacionadas con el desarrollo económico, la ampliación de la participación, la reducción de las desigualdades y la exclusión social y mejorar la calidad de vida, entre otros. Se espera, por consiguiente, que los Estados intervengan en dichos asuntos a través del diseño e implementación de políticas culturales. En este modelo, la ciudadanía actúa a través de movimientos sociales, posicionando diferentes temáticas en la agenda pública.

Otros trabajos previos que abordan las brechas de implementación de las políticas culturales argentinas (tanto nacionales como subnacionales) señalan que las carteras de cultura y sus funcionarios conciben a la cultura tanto en su registro antropológico como estético-ilustrado, pero, en la práctica, los esfuerzos se orientan mayormente hacia la promoción del acceso a bienes y productosartístico culturales (Mendes, 2015; Morais, 2018; Gutiérrez, 2019). Esto implica una convivencia de modelos democráticos y democratizantes en las políticas culturales.

En relación al plano municipal, Tasat (2009) reconoce una orientación hacia la oferta de servicios culturales, en el sentido de programación de eventos y espectáculos, la preservación del patrimonio cultural y las propuestas de formación artística. En consonancia, Mercadal (2020), al analizar las políticas culturales locales de Villa María (Argentina), registra una concepción difusionista de la cultura predominante, basada en fortalecer el acceso a bienes y servicios culturales. Resulta evidente, también, que se confunden políticas con programación de actividades, existiendo una tendencia a interpretar que el traslado de propuestas generadas desde la gestión cultural municipal a diferentes espacios de la ciudad conduciría a la inclusión o ampliación de públicos.

Despegándose de ese modelo de políticas, la retórica participacionista y localista está especialmente presente en las que se dieron en llamar políticas culturales comunitarias. Académicos y participantes de movimientos estético-políticos exaltan el carácter innovador y participativo de esas políticas que encuentran su germen en el Programa Cultura Viva implementado en Brasil a partir de 2004 (Gutiérrez, 2019; Infantino, 2019; Prato \& Segura, 2018). La novedad estaría puesta en que, en un proceso de construcción de la política pública de "abajo hacia arriba", el Estado reconoce las iniciativas culturales generadas en los territorios donde ocurren, así como sus propias necesidades y planes de trabajo.

La difusión de políticas culturales de base comunitaria en la región también tuvo su repercusión en las decisiones del Ministerio de Cultura de Argentina a través de su Programa Puntos de Cultura, en funcionamiento desde 2011. En una investigación previa (Gutiérrez, 2019), demostramos la relación entre las representaciones de la "cultura comunitaria", la formulación de políticas participativas y la instrumentalización de la cultura en Argentina (2011-2019).

El programa Puntos de Cultura en Argentina nació como una política de transferencia de recursos hacia organizaciones culturales comunitarias. Fue transformado su discurso, de la inclusión hacia la co-gestión, a partir de instrumentar ciertas instancias de concertación (Comisión Nacional de Puntos de Cultura y Consejo Federal de Cultura Comunitaria), habilitando la participación de representantes regionales en las decisiones de la política pública (Gutiérrez, 2019; Gutiérrez \& Sorribas, 2020).

Además, en un intento de conformar el "sector de la cultura comunitaria", obtuvieron difusión esos marcos interpretativos resonando en actores subnacionales. En consecuencia, se comienzan a 
implementar políticas de cultura bajo esa concepción de cultura a nivel provincial (Entre Ríos) y municipal (Córdoba). No obstante, el Programa Puntos de Cultura argentino continúa funcionando de manera centralizada, a diferencia de la experiencia brasileña, que traspasa sus recursos a gobiernos estaduales y municipalidades para efectuar las convocatorias en esos niveles. Los trabajos que indagan específicamente en la implementación de la descentralización de la política cultural comunitaria en Brasil (Cardoso, 2011; Lima, 2013; Souza, 2013), brindan pistas de utilidad para comprender las ventajas de ese modelo. Frente a la "paradoja de escala" (Gutiérrez \& Sorribas, 2020) la localización se presenta como una posibilidad de afrontar las debilidades de los Estados nacionales que diseñan políticas de Puntos de Cultura y de dar lugar/ participación a ámbitos estatales municipales o sub-municipales mejor articulados con actores colectivos e institucionales presentes en el territorio.

Los antecedentes recogidos confirman lo señalado por Bonet y Négrier (2018) en cuanto a la emergencia de nuevos modelos de políticas culturales. Esta no implica la eliminación de los paradigmas previos, lo que produce su coexistencia. Con más o menos predominancia de unos sobre otros en diferentes configuraciones del ecosistema plural de proyectos y políticas culturales, la superposición involucra paradigmas de excelencia cultural, democratización cultural, democracia cultural y economía creativa. Cada paradigma se relaciona con una visión específica sobre la participación.

Teniendo en cuenta las contribuciones hasta aquí sistematizadas, en el próximo apartado se reconstruye el estudio de caso que nos permite elaborar conclusiones sobre el modelo de política cultural y la concepción de la participación presentes en las políticas públicas vinculadas a la cultura comunitaria en Córdoba (Argentina).

\section{Políticas culturales en Córdoba}

\subsection{Resultados}

Los procesos participativos desarrollados en torno a la Ordenanza de Festejos Comunitarios de Carnaval y la Ordenanza de Promoción de la Cultura
Viva Comunitaria se encuentran emparentados, dado que involucran en Córdoba a una serie de participantes que ya tenían trayectoria en procesos de incidencia en legislación en materia de cultura a nivel nacional (Proyecto de Ley en Apoyo a la Cultura Comunitaria, Autogestiva e Independiente y Proyecto de Ley Federal de las Culturas).

Según los entrevistados que participaron en encuentros latinoamericanos de Cultura Viva Comunitaria, esas instancias propiciaron la consolidación de la identidad colectiva y, a su vez, funcionaron como estrategia de incidencia política. Esto se debe a que, en esos ámbitos, los referentes de las organizaciones tienen más posibilidades de interactuar con funcionarios estatales con injerencia en el diseño e implementación de políticas culturales de diversos niveles. Un entrevistado de la ciudad de Córdoba relata el proceso de incidencia en la ordenanza de "Festejos comunitarios del Carnaval" generada gracias al vínculo que pudo establecerse en un Congreso de Cultura Viva Comunitaria con funcionarios de la Secretaría de Cultura de la Municipalidad de Córdoba:

... cuando aparece esto de que se hacía el Congreso en Bolivia, ese fue el espacio de encuentro (...) Era una línea de trabajo invitar a funcionarios que pudieran ir, pudieran conocer, pudieran entender el por qué de Cultura Viva Comunitaria. Es un objetivo acercar a las políticas públicas y acercar a funcionarios que se interesen. Ellos viajan allá y con ellos comenzamos todo un proceso que termina, por ejemplo, en la Ordenanza de Carnaval (Entrevista HV, comunicación personal, 17 de marzo de 2017).

La ordenanza en cuestión (Ord. 12500/2015), aprobada el 30 de noviembre de 2015, en la Ciudad de Córdoba, promueve convocatorias anuales para apoyar con recursos económicos los Festejos Comunitarios de Carnaval, es decir

actividades, de entrada libre y gratuita, relacionadas con la citada fiesta popular, llevadas adelante durante los meses de febrero y marzo en espacios públicos de la Ciudad por agrupaciones de carnaval, organizaciones de la sociedad civil, centros vecinales, organizaciones barriales (...) cuya propuesta artística está integrada mayoritariamente por mascaradas, comparsas, bailes, desfile de murgas (...) y toda otra relacionada con la festividad" (Ordenanza No 12500; 2016, p.1). 
A partir del proceso de incidencia, se consiguió que la ordenanza contemple la cobertura de seguros de responsabilidad civil, cobertura médica y de seguridad para los beneficiarios, así como el apoyo de diferentes áreas operativas municipales que, con anterioridad a la legislación, debían autorizar la realización de festejos mediante numerosos trámites burocráticos.

Las "organizaciones de carnaval" de la ciudad de Córdoba fueron las primeras en generar acciones colectivas acompañadas por la Universidad $\mathrm{Na}$ cional de Córdoba y la Secretaría de Cultura Municipal. El proceso comenzó en 2012 a partir de la necesidad percibida de agilizar las habilitaciones para estas expresiones artísticas que tienen lugar en algunos territorios sub-municipales. La intención inicial era que la ordenanza contemplara todas las manifestaciones artístico-culturales que tuvieran lugar en la vía pública. Sin embargo, esto se vio imposibilitado debido a la escasa organización de esos otros sectores y la falta de interés en dialogar con el municipio por diferencias político-ideológicas con el partido oficialista.

Aunque haya habido un proceso participativo para obtener el apoyo municipal, lo comprometido por parte de la Secretaría está orientado a la oferta de servicios culturales, en el sentido de programación de eventos y espectáculos, la preservación del patrimonio cultural y las propuestas de formación artística. Esa característica es coherente con lo que señalaba Tasat (2009) al analizar otras políticas culturales municipales.

A su vez, esta política cultural podría considerarse bajo el enfoque del "modelo democrático" descrito por Mendes, en tanto que las acciones estatales promovidas fomentan la "participación de la ciudadanía en la vida cultural" $(2015$, p.96) y, como consecuencia, se espera que ésta cambie su actitud, desde la expectación a la participación. Como se menciona en la Ordenanza en cuestión, la Secretaría de Cultura será la encargada de "establecer los mecanismos de selección de los proyectos beneficiarios, como así también determinar las formas de apoyo, asegurando una amplia participación de las organizaciones comunitarias con la intención de promover nuevos festejos de carnaval" (Ord. 12500/2015).

El sentido subyacente de participación es el "ser parte" tanto de la fruición como en la producción cultural. Pero ello no implicaría participar también en las decisiones o criterios relativos a la implementación de la política cultural, como sí lo contempla la Ordenanza de Cultura Comunitaria, al prever un mecanismo de participación sostenido, el Consejo Municipal de Cultura Comunitaria.

Para la Ordenanza de Cultura, también los encuentros de Cultura Comunitaria len particular, el 3er Encuentro de Puntos de Cultura y 1er Encuentro de Redes de IberCultural tuvieron un rol importante. Esto es así dado que, más allá de convocar a los beneficiarios del Programa Puntos de Cultura, se invitó a una serie de organizaciones culturales comunitarias con trabajo territorial y funcionarios de las carteras de cultura de diversos municipios.

No éramos Punto de Cultura, pero éramos una organización invitada porque habíamos trabajado con Cultura de Barrio. Varias de las organizaciones que viajamos esa vez no éramos Puntos de Cultura pero sí teníamos trabajo acá en territorio. Ahí nos encontramos con Lucrecia ${ }^{1}$ (Entrevista M.B, comunicación personal, 7 de octubre de 2020).

Ese fue el puntapié inicial, según las fuentes entrevistadas, para abrir un espacio de diálogo importante a favor de la ordenanza de Promoción de la Cultura Comunitaria en Córdoba. De esa manera, se consolidó un proceso participativo, aprovechando la capacidad organizativa y los conocimientos de actores que ya estaban movilizados y compartían un lenguaje y una trayectoria de activismo. El proceso redundó en la generación de conocimiento experto tanto en actores colectivos como en los funcionarios que continuaron en sus cargos.

En dicho proceso de incidencia, una entrevistada señala que es importante la receptividad de parte de los funcionarios para que se genere ese proceso participativo, pero lo distingue de una receptividad general, considerando la complejidad estatal y alejándose de una visión monolítica:

No fue el Estado el que decidió, sino que fuimos nosotros a la par de integrantes del Estado (...) no creas que todo el Estado, como una cuestión homogénea, sino que estas dos personas que saben de qué se trata y saben el valor estratégico de este instrumento legal para las organizaciones de cultura comunitaria. Entonces, teníamos ahí como “compañeros en la lucha" que están justamente en lugares 
estratégicos que nos ayudaron a nosotros a poner esta ordenanza y que saliera (Entrevista M.B, comunicación personal, 7 de octubre de 2020).

Esto es relevante dado que confirma que la proximidad de las autoridades locales con la ciudadanía favorece que se ocupen más directamente de los problemas de ésta, canalizándolas en las decisiones de políticas públicas.

Sin embargo, los grupos más organizados o articulados en red, con mayor interés/activismo y que tienen contacto con funcionarios de las gestiones culturales municipales, son los que lograron efectivamente participar en el diseño de programas culturales o en la legislación. Esto comprueba que la democratización y los procesos participativos a nivel local se distribuyen de manera diferencial entre áreas sub municipales (territoriales y administrativas).

Por otro lado, el Consejo Municipal de Cultura Comunitaria, en tanto instancia de participación institucionalizada, no se encuentra en funcionamiento. Según los entrevistados, esa paralización se debe a que no se ha reglamentado aún la cantidad y renovación de integrantes para que exista una efectiva participación de las organizaciones culturales comunitarias.

\subsection{Discusión}

Existe una fuerte retórica participacionista en las acciones y discursos de las políticas culturales comunitarias que se difundieron desde Brasil ${ }^{2}$ a otros países, regiones y localidades de Iberoamérica. En Argentina, la articulación en redes del Movimiento Cultura Viva Comunitaria propició diferentes acciones colectivas para la incidencia en la legislación y en el diseño e implementación de políticas sectoriales a nivel nacional. En el caso de Córdoba, también a nivel municipal. Asimismo, estas políticas culturales incorporan innovaciones democráticas en carácter de "órganos de participación", como el Consejo Cultural Comunitario, la Comisión Nacional de Puntos de Cultura o el Consejo Municipal de Cultura Comunitaria de Córdoba. Sin embargo, según se observa, la alusión a la participación en los discursos analizados tiene más que ver con el intento de desmarcarse de las "políticas culturales de democratización por acceso" o difusionistas, esperando de los beneficiarios de esas políticas un rol "protagónico".

En la elaboración de ordenanzas como la de Festejos comunitarios de Carnaval (Ordenanza 12500/2015) y la Promoción de la Cultura Viva Comunitaria (Ordenanza 12957/2019), el proceso participativo no surgió inicialmente de la institucionalidad participativa, sino por iniciativa de la acción colectiva. Sin embargo, los funcionarios de la cartera de cultura mostraron receptividad y brindaron una serie de alternativas que los sectores movilizados pudieron interpretar como oportunidades políticas (Leiras, 2007).

En el caso de la Ordenanza de Promoción de la Cultura Viva Comunitaria se incorporó un órgano, el "Consejo Municipal de Cultura Comunitaria", habiendo tomado como modelo políticas culturales de base comunitaria de otras ciudades de América Latina e intentando dotar a los colectivos del sector de posibilidades para la toma de decisiones de la política institucional. Tras la sanción de la ordenanza, queda pendiente poner en funcionamiento efectivo dicha instancia, debido a que en el texto de la norma no estaban aún establecidas cuestiones fundamentales como la cantidad de integrantes, la procedencia sectorial o el procedimiento de renovación de los miembros. La importancia de avanzar en la reglamentación reside en la necesidad de renovar la participación, dado que la primera conformación tenía la intención de servir como antecedente. Pasada esa primera instancia participativa ad hoc para la redacción de la ordenanza, el Consejo requiere:

que se reglamente y que se elija con otra metodología, que no sea a dedo, sino que sean realmente representativos los integrantes (...) para que se vaya a dialogar así, con la Provincia, con el Municipio, con quien corresponda. Inclusive con otras organizaciones de cultura comunitaria que no se identifican como tales y hace mucho tiempo que están haciendo trabajo en el territorio (Entrevista M.B., comunicación personal, 7 de octubre de 2020).

La narrativa de valorización de las políticas culturales comunitarias subnacionales puede rastrearse en la transformación de la política cultural Puntos de Cultura durante la presidencia de Mauricio Macri (2015-2019). Ante las medidas de ajuste inspiradas por su proyecto político neolibe- 
ral, el desfinanciamiento y la desjerarquización del Ministerio de Cultura, la voluntad de los decisores políticos a cargo de la política pública oficial jugó un rol fundamental para "conformar el sector de la Cultura Comunitaria"3 (Gutiérrez, 2019). Se activaron los mecanismos de participación previstos desde el inicio del Programa Nacional Puntos de Cultura (2011) y se propusieron espacios de encuentro entre miembros del movimiento de Cultura Viva Comunitaria, beneficiarios de Puntos de Cultura y funcionarios estatales de niveles provinciales y municipales para que actúen como "difusores" (Romanutti, 2018) de políticas culturales de base comunitaria de alcance local.

En el caso de las políticas culturales locales abordadas, se demostró que pudieron ser aprovechados los beneficios de la proximidad o cercanía con las autoridades para canalizar ciertas necesidades del sector de la cultura comunitaria. Sin embargo, esa apertura a la participación estuvo desigualmente distribuida dado que ni las posibilidades de incidencia ni todavía el mecanismo de participación previsto habilitó la participación de otras organizaciones de sectores culturales afines a la cultura comunitaria, barrial o territorial.

Consideramos que la participación se constituye eminentemente en una retórica de las políticas culturales locales aquí abordadas, sujeta a dos modelos de políticas culturales. Por un lado, a aquel que cifra la participación como posibilidad de intervenir en el campo artístico, no solo en la fruición sino también en la producción, otorgándole a la ciudadanía un rol más activo que en las políticas culturales de corte difusionista. Por el otro, al modelo recursista, en tanto que la política cultural se legitima a sí misma en su carácter instrumental, con el propósito de abordar diversos problemas, como, por ejemplo, la demanda por mayor inclusión y la ampliación de la participación ciudadana.

\section{Conclusión}

En América Latina, las diversas formas de la participación ciudadana han surgido como innovaciones democráticas (con un importante desarrollo en Brasil) y han sido institucionalizadas con la pretensión de enriquecer la democracia local y ampliar la intervención de la ciudadanía en el campo de decisiones que le afectan. Sin embargo, los órganos de participación también se han configurado como instancias de legitimación de decisiones de funcionarios o influenciadas por élites que tienen una participación desproporcionada en el proceso de toma de decisiones.

En relación a eso, el estudio de caso presentado en este trabajo constituye una evidencia importante para sustentar la hipótesis de la participación instrumental. Esto es, que la dimensión de la participación se desenvuelve en un plano retórico y permite asignarle un rol más activo y propositivo a sus beneficiarios. A la par, dichas políticas culturales son legitimadas por la ciudadanía por el mero hecho de concebirse como un ámbito más en donde es posible decidir sobre asuntos públicos, aunque la evidencia demuestre que las decisiones tomadas de manera participativa no son sustanciales o la participación se distribuye de manera desigual. Esa legitimación está asentada en el supuesto que "si la participación es importante para esa política, entonces la política pública será mejor" (DupinMeynard \& Négrier, 2020, p.11).

Por lo dicho, confirmamos que la escala local en las políticas culturales no significa necesariamente mayores niveles de participación efectiva, pero sí propicia el uso instrumental de la participación como forma de legitimación de la acción pública.

Asimismo, el estudio de caso confirma la hipótesis de la participación corporativa. Varias voces críticas de la institucionalidad participativa señalan que la ampliación de la participación suele producirse al interior de la sociedad política. Esto es, que se reproducen las tradicionales relaciones de poder entre los sistemas técnico-políticos y una ciudadanía cuyo repertorio obedece a prácticas partidariaselectorales (Sorribas \& Gutiérrez, 2021; Echavarría et al., 2021)

En suma, aunque se piense a las ciudades ly sus gobiernos locales) como "protagonistas" del cambio social, se incorpore a la sociedad civil en la formulación y monitoreo de las políticas públicas mediante la participación ciudadana o se intente democratizar la cultura mediante políticas que se adapten a las necesidades del territorio, no hay garantías de la reducción de las desigualdades generadas por la gobernanza neoliberal. 
Más bien, estos terrenos se configuran como campos de disputa en sí mismos, donde los sentidos que circulan pueden estar asociados más a un proyecto neoliberal que a uno democrático participativo, o viceversa, y en donde juega un rol decisivo la subjetivación política“ (individual y colectiva) de quienes intervienen en esa disputa.

Trascendiendo la perspectiva liberal de la democracia laquella vinculada a un Estado de Derecho que se presupone incluyente), otros análisis son posibles. Entender a la democracia asociada al despliegue de acciones conflictivas que hacen ver "como comunes a sujetos y problemas que antes no eran considerados como parte del espacio establecido como común" (Quintana, 2015, p.76), habilita nuevas reflexiones. Aquellas que no sólo consideren los efectos de la incidencia de los movimientos o acciones colectivas en la fijación de agendas de los Estados, sino que hagan foco también en la búsqueda de nuevos significados por parte de esos movimientos, en torno a lo cultural y lo participativo. Construcción de sentidos que pone en marcha una política cultural en sí misma.

\section{Notas}

1. En referencia a una funcionaria de la Dirección de Cultura Comunitaria lactualmente Dirección de Cultura Viva).

2. El programa Cultura Viva de Brasil, transformado en 2014 en política de Estado mediante la ley 13018, es uno de varios modelos de políticas que se han imitado en otros paises. De manera similar, sucedió con políticas públicas como Bolsa Família, Fome Zero (Hambre Zero) y el Presupuesto Participativo (Gutiérrez, 2019).

3. La cita corresponde a una entrevista con funcionarios a cargo del Programa Puntos de Cultura del Ministerio de Cultura de la Nación realizada en 2018 en el marco de una tesis de maestría. El corpus de la investigación referida estuvo conformado tanto por fuentes primarias lobservaciones participantes en encuentros de Cultura Viva Comunitaria y Puntos de Cultura y entrevistas semiestructuradas) como fuentes secundarias (resoluciones ministeriales).

4. El vínculo con el Estado, la confrontación con las maneras tradicionales de entender la participación política y la militancia territorial, y la visibilización de las desigualdades producidas por procesos de centralización geográfica, son las dimensiones que asociamos a la subjetivación política de los colectivos culturales comunitarios. Para un debate detallado, ver Gutiérrez (2020).

\section{Referencias}

Basile, M.V (2020). Las políticas culturales municipales en los años noventa. El caso de la ciudad de Córdoba (Argentina, 1991 -2003). Mediaciones, 16(25), 142-157. https://doi.org/10.26620/ uniminuto.mediaciones.16.25.2020.142-157

Bookchin, M. (2015) The Next Revolution. Verso.

Bonet, L. \& Négrier, E. (2018). The participative turn in cultural policy: Paradigms, models, contexts. Poetics, 66, 64-73.https://doi.org/10.1016/j.poetic.2018.02.006

Brown, W. (2016) El pueblo sin atributos. La secreta revolución del neoliberalismo. Malpaso.

Calabre, L.(2010) Políticas culturais no Brasil: história e contemporaneidade. Banco do Nordeste do Brasil.

Cardoso, S. (2011). Programa Cultura Viva e seu processo de estadualização na Bahia. (Tesis de maestría). Faculdade de Comunicação, Universidade Federal da Bahia.

Dagnino, E. (2018) “Confluencia perversa, desplazamiento de sentido, crisis discursiva”. En B. Bringel \& A. Brasil (Coords), Antología del pensamiento crítico brasileño contemporáneo (pp. 679-700). CLACSO.

Dupin-Meynard, F. \& Négrier, E. (2020) Cultural Policies in Europe: a Participatory Turn?. Éditions de l'Attribut. 
Echavarría, C., Sorribas, P., Romanutti, V., Gutiérrez, M., \& Cinco Chavez, D. (2021). La participación de la ciudadanía en Córdoba desde un abordaje multidisciplinario: principales tendencias y nuevos interrogantes. XIV Congreso Nacional y VII Congreso Internacional sobre Democracia, Rosario, Argentina.

Gutiérrez, M. (2019) La “Cultura Comunitaria” como práctica y como política pública: Un análisis desde la perspectiva de actores colectivos e institucionales [Tesis de Maestría en Sociología] Universidad Nacional de Córdoba

Gutiérrez, M. (2020) De beneficiarios de una política cultural a subjetividades políticas: uso político de derechos y experimentación política en la Cultura Comunitaria argentina. Methaodos Revista de Ciencias Sociales, 8 (1) 50 - 61 https://doi.org/10.17502/m.rcs.v8i1.335

Gutiérrez, M. \& Sorribas, P. (2020) Acciones colectivas y políticas culturales de base comunitaria. Cartografías del Sur. Revista de Ciencias, Artes y Tecnología 12 (1) 252-285 https://doi. org/10.35428/cds.vi12.198

Infantino J. (2019), Disputar la cultura. Arte y Transformación social. RGC.

Leiras, M. (2007). “La incidencia de las organizaciones de la sociedad civil en las politicas públicas. Definiciones, explicaciones y evaluaciones de la literatura especializada local e internaciona". En C. Acuña, \& A. Vacchieri (Comps.), La incidencia política de la sociedad civil (pp. 17- 66). Siglo XXI .

Lima, L.(2013). Desafios jurídicos e administrativos da política cultural comunitária: um estudo dos Pontos de Cultura no estado de São Paulo. (Tesis de Maestría). Universidade de São Paulo.

Mendes, P. (2012) Las políticas culturales de los gobiernos locales en la Argentina. Rev. pueblos front. digit., 7(13) 127-146. http://www.scielo.org.mx/scielo.php?script=sci_ arttext\&pid=S1870-41152012000100005\&lng=es\&nrm=iso.

Mendes, P. (2015) Políticas Culturales: Rumbo y deriva. RGC libros.

Mercadal, S. (2020). Creación y sociedad: la gestión cultural pública en Villa María. Lago Editora.

Moini, G. (2017). Participation, neoliberalism and depoliticisation of public action. SocietàMutamentoPolitica, 8(15), 129-145.https://doi.org/10.13128/SMP-20853

Morais, I. P. (2018). Cartas, juegos y naipes. Producción teórica sobre sociedad civil y políticas culturales argentinas entre 2002 y 2017. En V. Prato \& S. Segura (Comps.), Estado, sociedad civil y políticas culturales: rupturas y continuidades en Argentina entre 2003 y 2017. RGC Libros.

Pérez, M.\& Navarro, C. (2000) Política y sociedad en el ámbito local: el nuevo localismo, Foro Internacional, 161,451-466. https://forointernacional.colmex.mx/index.php/fi/article/view/1574/1564

Piñero, M.T. (2019) Micropolíticas de neoliberalismo punitivo en Argentina. En M.T. Piñero \&J. Foa Torres (Comp), Neoliberalismo: Aproximaciones a las razones de su éxito. (pp. 11-26). Cuadernos de Investigación. CEA. FCS

Pratchett, L. (2004) Local Autonomy, Local Democracy and the 'New Localism'. Political

Studies, 52, 358-375.https://doi.org/10.1111/j.1467-9248.2004.00484.x

Prato, A. V. \& Segura, M. S. (2018). Estado, sociedad civil y políticas culturales: rupturas y continuidades en Argentina entre 2003 y 2017. RGC Libros.

Quintana, L. (2015). ¿Un derecho que no es un derecho? El derecho como estructura política del desacuerdo, Ciencia Política, 10 (19), 69-93. https://doi.org/10.31381/inkarri.v0i6.1230

Romanutti, V. (2018). Listos para ser usados: el papel de los difusores de procedimientos participativos en la planificación urbana local. [Presentación de Ponencia]. Primer Congreso Nacional de Ciencias Sociales, Facultad de Ciencias Sociales, Universidad Nacional de Córdoba, Córdoba, Argentina.

Rubim, A., Fernandes, T., \& Rubim, I. (2010). Políticas culturais, democracia e conselhos de cultura. EDUFBA. 
Sorribas, P. \& Garay, Z.(2014). La participación, entre la democracia participativa y la democracia directa: Aportes desde un enfoque psicosocial. Polis, 2 (10), 39-69. http://scielo.org.mx/ scielo.php?script=sci_arttext\&pid=S1870-23332014000200003

Sorribas, P., Eberhart, L. \& Gutiérrez, M. (2016) Instituciones de democracia participativa en Córdoba. Una aproximación al análisis de organizaciones sociales participantes y sus vínculos con partidos políticos. XII Congreso Nacional y V Congreso Internacional sobre Democracia. Rosario.

Sorribas, P. \& Gutiérrez, M. (2021). Inovações democráticas na perspectiva de seus participantes. Uma abordagem para o ajuste social percebido. Revista Debates, 15 (1), 143-167. https:// doi.org/10.22456/1982-5269.110386

Souza, C. (2013). Pontos de cultura: uma inflexão na política cultural brasileira?. (Tesis de Maestría). Universidade Federal da Bahia.

Tasat, J. (2009). Políticas Culturales de los gobiernos locales en el conurbano bonaerense. En Indicadores Culturales 2009 (pp. 61-70). EDUNTREF. http://www.untref.edu.ar/documentos/ indicadores_culturales/2009/Politicas\%20-\%20Jose\%20Alejandro\%20Tasat.pdf

Thompson, M. (2020). What's so new about New Municipalism? Progress in Human Geography. 44 (1) 1-26 https://doi.org/10.1177/0309132520909480

Yúdice, G. (2002) El recurso de la cultura. Gedisa.

Yúdice, G. (2019). Políticas culturales y ciudadanía. Educação \& Realidade, 44 (4)1-24.https://doi. org/10.1590/2175-623689221

Zárate, L. (2020) “Lecciones pandémicas, derecho a la ciudad y nuevo municipalismo Transformaciones que no pueden esperar". En M. Dammert-Guardia, P. Vommaro \& L. Bonilla. (2020) Múltiples miradas para renovar una agenda urbana en crisis (pp. 44 - 56). CLACSO. Recuperado de: https://www.clacso.org/wp-content/uploads/2020/10/Desigualdades-urbanas_N1.pdf

- Sobre la autora:

Mariana Gutiérrez es Doctoranda en Ciencia Política, Magíster en Sociología y Licenciada en Administración por la Universidad Nacional de Córdoba (UNC). Becaria doctoral cofinanciada por el Consejo Nacional de Investigaciones Científicas y Técnicas (Argentina) y la UNC.

- ¿Cómo citar?

Gutiérrez, M. (2021). La ciudad como panacea: políticas culturales comunitarias y participación en Córdoba (Argentina). Comunicación y Medios. (44), 118-129. https://doi. org/10.5354/0719-1529.2021.61456 